\title{
EQUILIBRIUM ANALYSIS OF A SAIL VAULT IN LIVORNO'S FORTEZZA VECCHIA THROUGH A MODERN RE-EDITION OF THE STABILITY AREA METHOD
}

\author{
Danila Aita $^{1}$, Riccardo Barsotti ${ }^{1}$, and Stefano Bennati ${ }^{1}$ \\ ${ }^{1}$ Department of Civil and Industrial Engineering, University of Pisa \\ Largo Lucio Lazzarino, Pisa, Italy \\ e-mail: danila.aita@unipi.it, \{r.barsotti, s.bennati\}@ing.unipi.it
}

Keywords: Masonry dome, Fortezza Vecchia in Livorno, Limit Analysis, Durand-Claye.

\begin{abstract}
The present paper aims at performing a preliminary study of the mechanical response of a sail vault covering a trapezoidal room located in the Cavaniglia bastion of Fortezza Vecchia in Livorno. In particular, admissible stress fields within the vault have been determined by considering the weight of the vault itself and that of the overlying soil layers. The analysis has been conducted by means of a re-visitation of the stability area method, an interesting historical method proposed by Durand-Claye. The method is suitably extended in order to assess the stability of an entire dome under the assumption of nil tensile hoop forces.
\end{abstract}




\section{INTRODUCTION}

This contribution is framed within a research project (PRA 2017 - "Tuscan Renaissance architecture: case studies between historical investigation, survey and structural analysis”), promoted by the University of Pisa. This interdisciplinary research aims at studying some buildings of significant interest from a historical and architectural point of view. The structures chosen can be considered representative of $15^{\text {th }}$ - and $16^{\text {th }}$ - century Tuscan architecture.

One of the most interesting buildings examined within this project is the Fortezza Vecchia (the Old Fortress) in Livorno, a maritime castle of great historical interest, built on behalf of the Florentine government. Although its oldest parts date back to the Middle Ages, the castle was substantially reshaped in the $16^{\text {th }}$ century by Giuliano and Antonio the Elder da Sangallo, who enlarged it. The modifications performed took into account the nature of the site and the pre-existing medieval structures [1].

The present paper is aimed at illustrating a preliminary study of the mechanical response of a sail vault covering a quadrilateral room located in the Cavaniglia bastion of the Fortezza Vecchia (Fig. 1).
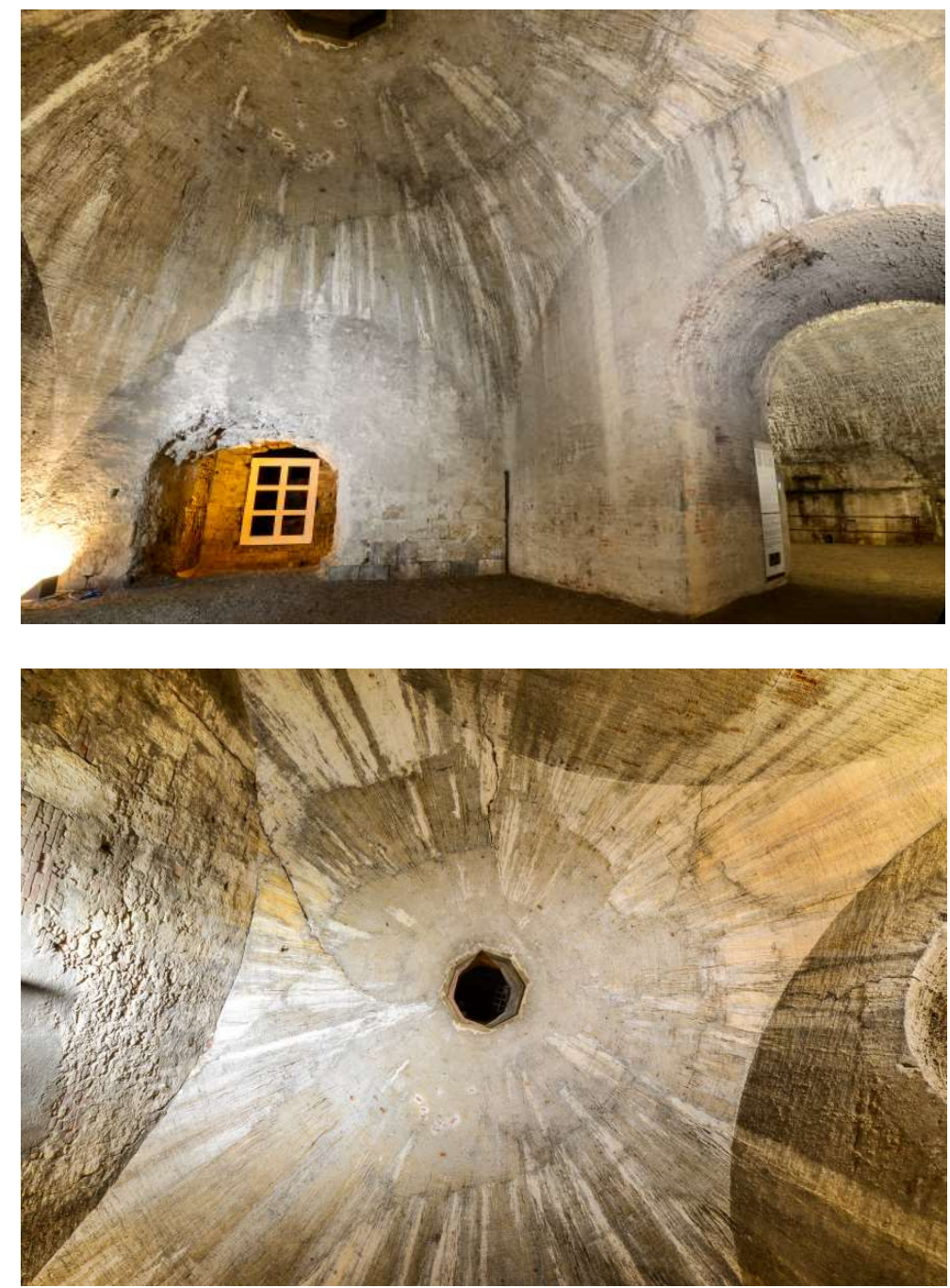

Fig. 1. Sail vault in the Cavaniglia bastion of Fortezza Vecchia: the intrados spherical surface with pendentives (above); the octagonal oculus and radial brick bonds (below). 
A reliable survey of the sail vault is the essential starting point for adequately detailed structural modeling. Thus, both range-based (laser scanning) and image-based (3D Photogrammetry) survey methodologies have been planned, though not yet complete. In particular, in this first stage, an accurate CAD representation of the dome intrados has been constructed using the results of laser scans (Fig. 2).

The structural analysis has been performed by means of a re-visitation of the stability area method, an interesting historical method proposed by Durand-Claye. Originally designed for masonry arches, in 1880 [2] the French scholar extended it to domes of revolution, provided the dome is subdivided into several lunes, obtained by ideally sectioning the dome with meridian planes. Durand-Claye's contribution consists of applying his method to each lune, considered as an independent arch of varying width.
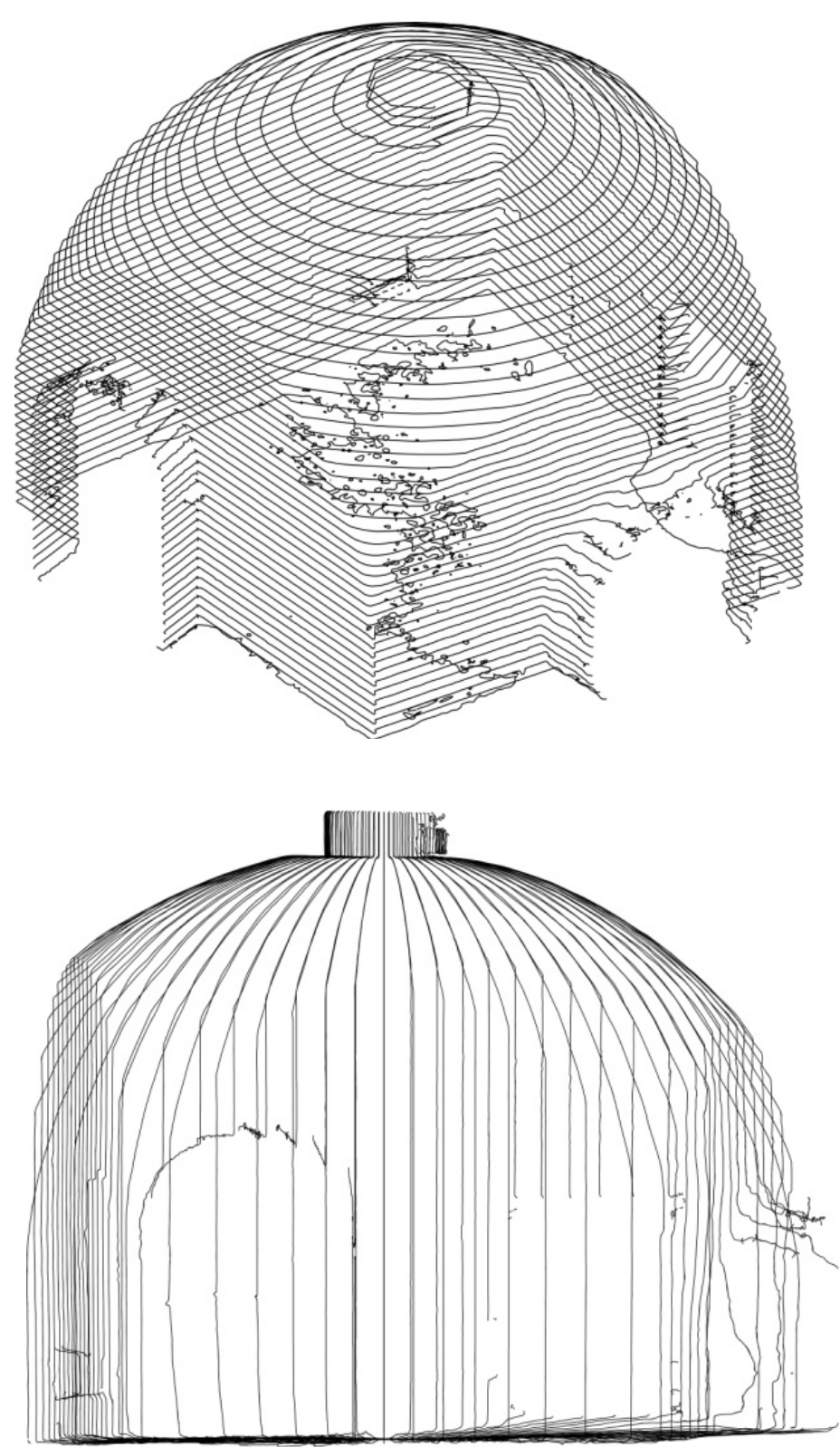

Fig. 2. Survey of sail vault's intrados: horizontal sections (above) and radial vertical sections (below), in CAD format. 
In previous contributions the authors re-elaborated Durand-Claye's method in order to assess the stability of masonry arches [3] and domes of revolution $[4,5,6]$ subject to symmetrical load distributions. The method has been suitably extended in order to assess the stability of an entire dome by assuming nil tensile hoop forces and admitting compressive hoop forces in the upper portion of the dome. In the present contribution, the reworked Durand-Claye method, implemented in an expressly developed numerical tool, is used to assess the stability of the sail vault in the Fortezza Vecchia under vertical loads.

\section{STRUCTURAL ANALYSIS OF SAIL VAULTS: A BRIEF OVERVIEW}

The structural analysis of masonry sail vaults is a subject rarely addressed in the current literature. Assessment of sail vault stability can be performed within the framework of limit analysis by assuming Heyman's hypotheses for a masonry-like material [7-11]: sliding failure does not occur; the material has an infinite compressive strength; the material is incapable of withstanding tension. In particular, the safe theorem states that, for standard materials, if it is possible to find an internal system of forces which is both in equilibrium with the loads and respects the assumptions recalled above, the structure is to be considered 'safe'.

A sail vault, similarly to a dome, can be imagined as made up of a series of arches obtained by suitably 'slicing' the vault into so-called 'lunes'. Each arch formed by two opposite lunes is safe if it is possible to draw a line of thrust within the same arch. According to Huerta [7], this technique was firstly applied to domes by Bouguer [12], and explicitly by Frézier [13], who adopts the slicing technique for voutes sphériques et spheroids in a qualitative manner. A brief account of the evolution of the mechanical interpretation of masonry domes is given in [4,6], where the different approaches (limit analysis, finite element analysis, complex computational method based on homogenization techniques, etc.) are briefly described.

The slicing technique was taken up by Heyman [8-11], who applied and framed it rigorously within the theory of plasticity. This technique has since been adopted for the assessment of different types of vaults. The procedure described in the following recent contributions presents some methodological issues that can be transferred to the assessment of sail vaults. With reference to a gothic quadripartite vault, [14] shows that the results of equilibrium analysis are dependent on how the vault is sliced, and that the limit states are moreover difficult to predict for complex vaults. An interesting application is also provided in $[15,16]$ for a square pavilion vault, in which the limit state analysis is conducted by taking into account finite friction. In this case, the most extensive cracking occurs in the diagonal region, and the authors observe that the lateral slices tend to behave almost as independent arches, whereas the central region cracks only in the lower portion.

As regards more specifically the structural response of sail vaults, some recent contributions can be cited, though without any attempt at completeness. One significant application has been put forth by Calderini [17], who considers the influence of the geometry in which the bricks are laid in a sail vault. The analysis is performed by means of a finite element model and the solution depends on the different brick bonds used (more precisely, a radial brick sail vault and a pitched brick sail vault are considered). In [18] Mousavian and Mehdizadeh Saradj present a parametric framework to analyze the constructability of masonry sail vaults in the early design stage. More precisely, finite element analysis is used to examine the structural stability of a sail vault during its construction. The algorithm also allows for calculating the material properties of fresh mortar, which change during construction. A further application of limit analysis to sail vaults is provided in another contribution within the same research project as the current paper [19]. In this case, the search for the lower-bounds estimate 
of the safety factor is conducted by considering the vault as a thin shell endowed with suitable membrane and bending stress fields.

\section{GEOMETRICAL AND MECHANICAL PARAMETERS CHARACTERIZING THE SAIL VAULT IN FORTEZZA VECCHIA}

The starting point for performing an adequate structural modeling of the sail vault is obviously a reliable survey. The sail vault intrados survey carried out by means of a range-based (laser scanning) methodology was made available by the Port System Authority of the Northern Tyrrhenian Sea. Up to the present stage of the research, a set of the vault intrados' horizontal and vertical radial sections have been obtained in CAD format via post-processing (Fig. 2), and a representative subset of points has been selected. The "best" approximating smooth surface was then determined through a minimization routine in Mathematica ${ }^{\circledR}$, described in more detail in [19].

By assuming that the intrados ideal surface is spherical, limited by four vertical planes, the procedure enabled obtaining the intrados radius $(5.51 \mathrm{~m})$, as well as the analytical expressions defining the vertical planes.

In order to perform a first assessment of the sail vault's stability, with reference to Fig. 3b, a constant thickness $h=0.25 \mathrm{~m}$ in the radial direction has been assumed (this value is a preliminary estimate, to be confirmed by planned future surveys). Furthermore, $a=0.85 \mathrm{~m}, b=0.35 \mathrm{~m}$, $c=3.14 \mathrm{~m}$, and $d=1 \mathrm{~m}$. A specific weight of $18 \mathrm{kN} / \mathrm{m}^{3}$ has been assumed for the vault, the 'lantern' and the overlying soil.
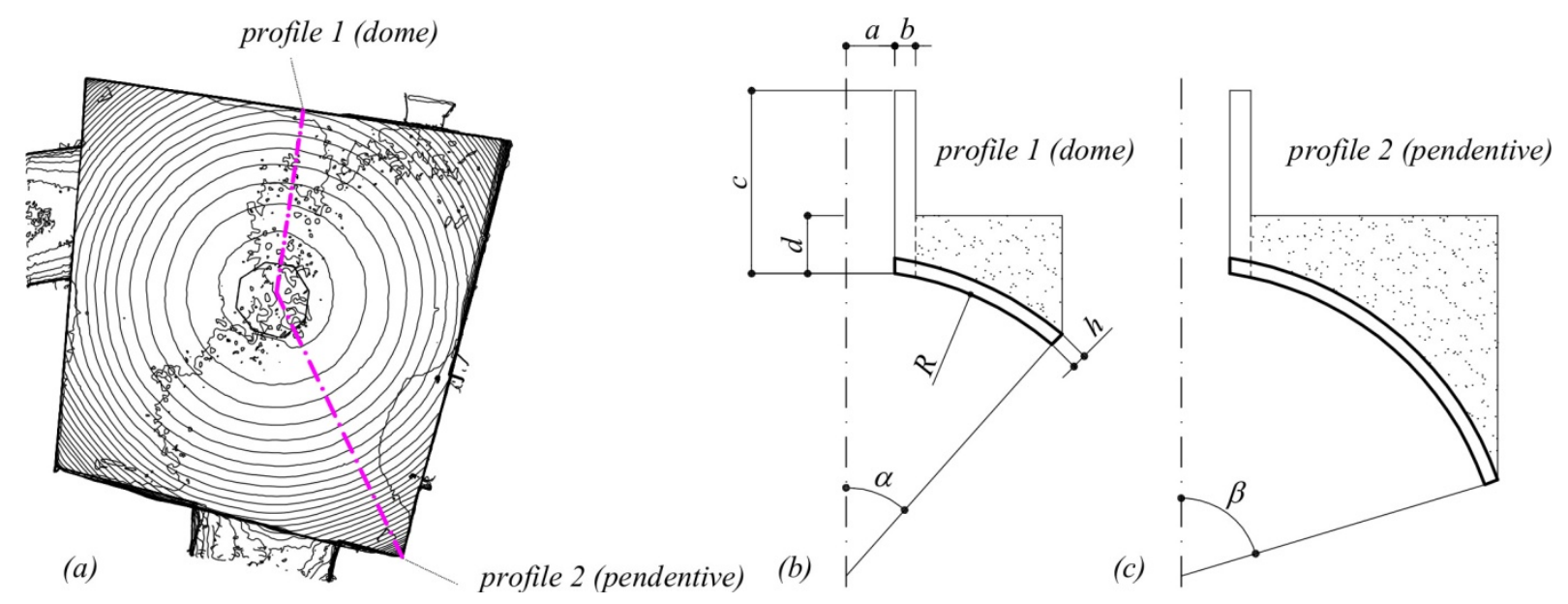

Fig. 3. The quadrilateral plan (a); profile 1, corresponding to the 'dome' above angle $\alpha=40.11^{\circ}(b)$; profile 2 , corresponding to the pendentive of maximum embrace angle, $\beta=70.79^{\circ}(\mathrm{c})$. 


\section{ASSESSMENT OF THE SAIL VAULT STABILITY}

The final objective of the present research project is to describe the structural behaviour of sail vaults by taking into account their geometrical and mechanical parameters, as well as construction aspects. At the present stage, analytical models have been developed based on limit analysis (review of the Durand-Claye method [3-6], identification of statically admissible stress fields $[19,20])$. Deeper analyses will be performed in following stages.

\subsection{A modern version of Durand-Claye's method for equilibrium analysis of sail vaults}

In this section a revised version of Durand-Claye's method will be applied in order to perform a first evaluation of the stability of the sail vault in Fortezza Vecchia. The method has been extensively described in [6] for masonry domes. For the purposes of the current work, it is sufficient to recall that Durand-Claye's method was originally conceived for masonry arches [21]. In [2] the French scholar extends his stability area method in order to assess the equilibrium of domes of revolution by applying his procedure to each single lune making up a dome. The stability area is determined under the hypotheses of limited compressive and tensile strength.

In previous papers, the authors have proposed a modern version of Durand-Claye's method by translating the complex graphical construction into a suitable set of equations in terms of the internal forces [3]. Furthermore, the method has been re-edited for domes in order to adequately take into account the influence of hoop forces and some kinematic aspects [4-6].

Strictly speaking, the sail vault is not a dome, but its central portion, above angle $\alpha=40.11^{\circ}$ (Fig. 3b) is a dome of revolution. Furthermore, pendentives are shaped according to the same sphere describing the dome. For the purposes of the present paper, bricks are assumed to be laid radially. In the following analysis it is assumed that the octagonal oculus - approximated by a circle - acts as a rigid ring subject to compressive hoop forces. It is moreover assumed that this ring is able to distribute the compressive forces at the dome top, effectively acting as a keystone.

A first equilibrium assessment can be conducted by applying Durand-Claye's method to a lune belonging to the dome of embrace angle $\alpha=40.11^{\circ}$, starting the analysis from the dashed vertical line (Fig. 3b) and considering, as an example, an amplitude of $1^{\circ}$ and infinite compressive strength. Each lune is ideally subdivided into 30 voussoirs. In Fig. 4a, the red and blue curves correspond to the attainment of a positive or negative limit bending moment at each joint (assumed in the radial direction). The stability area is the green-hatched area bounded by the aforementioned limit curves. By referring to the same notation adopted in [6], it is defined as the locus of the points $(P, e)$ - where $P$ is the crown thrust, $e$ its eccentricity with respect to the centre of the crown section - corresponding to statically admissible solutions under the hypothesis of nil hoop forces, i.e., for the single lune. Since the stability area is extended, the lune is in equilibrium even if compressive hoop forces are assumed to be nil. The thrust lines corresponding to the minimum (point A) and maximum (point B) value of the horizontal thrust $P$ are contained within the lune's thickness (Fig. 4b). A similar result is obtained even if finite compressive strength, $\sigma_{c}=20 \mathrm{MPa}$, is assumed for the masonry. 


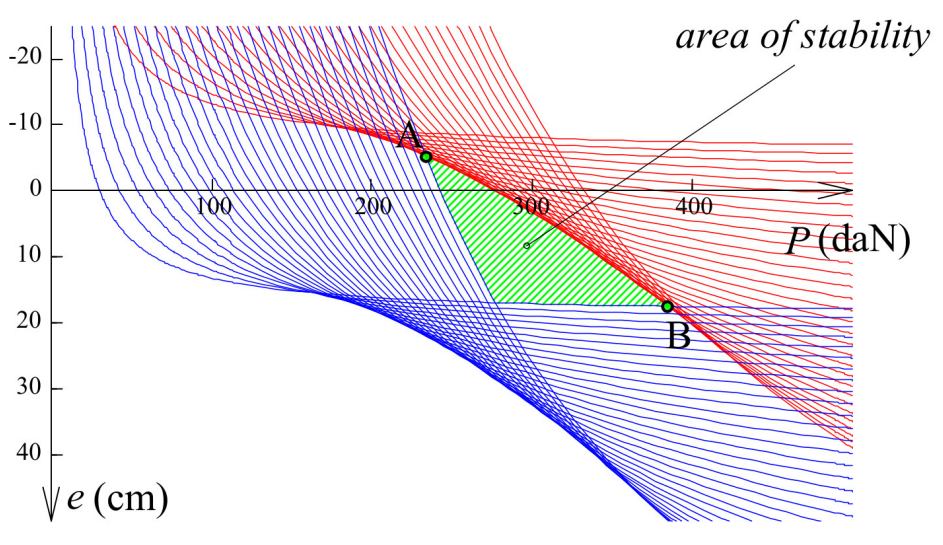

(a)
(A)

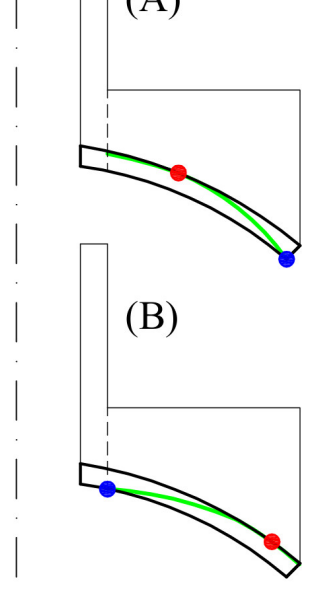

(b)

Fig. 4. The stability area related to the dome defined by $\alpha=40.11^{\circ}(a)$; the maximum and minimum thrust lines are contained within lune's thickness $(b)$.

The slicing technique can also be applied in order to obtain a rough assessment of the stability of the pendentives by analyzing a lune defined by $\beta=70.79^{\circ}$ (Fig. 3c), corresponding to the maximum embrace angle. Also in this case, the stability area plotted in Fig. 5a for an infinite value of compressive strength is extended, even if noticeably reduced with respect to that in Fig. 4a. The thrust lines corresponding to the maximum and minimum horizontal thrust values (Fig. 5b), which are almost coincident, do not exit the lune's thickness, and the lune is in equilibrium even for nil compressive hoop forces. Once again, even when assuming limited compressive strength, $\sigma_{c}=20 \mathrm{MPa}$, an analogous output is obtained.

It is noteworthy that the stability areas plotted for both lunes under examination (Fig. 4 and Fig. 5) are more or less extended. The sail vault of Fortezza Vecchia is thus far from any collapse condition. Moreover, even if the stability area were reduced to a single point by progressively reducing the lune's thickness, $h$, this would not lead to a limit condition, since the collapse mechanism identified by the vanishing of the stability area would not be a kinematically admissible mechanism for the dome considered as a whole. In this case, the lateral surfaces of each lune would act as constraints, by preventing inwards motion.

As already observed in [4-6], according to a symmetric admissible collapse mechanism for the entire dome, the central part of the dome does not deform, but descends vertically; below, adjacent lunes move apart to form extrados and intrados hinges (starting from the lune's 'crown', first an extrados hinge is formed, then an intrados hinge, and finally another extrados hinge). By decreasing the thickness, a limit condition can be identified according to the procedure adopted in [6], so as to check for lune stability under the restriction that only an admissible collapse mode can occur by admitting the presence of compressive hoop forces in the upper part of the vault. As regards the dome identified by $\alpha=40.11^{\circ}$, this procedure shows that an admissible collapse mechanism does not occur even for a vanishing value of the thickness. 


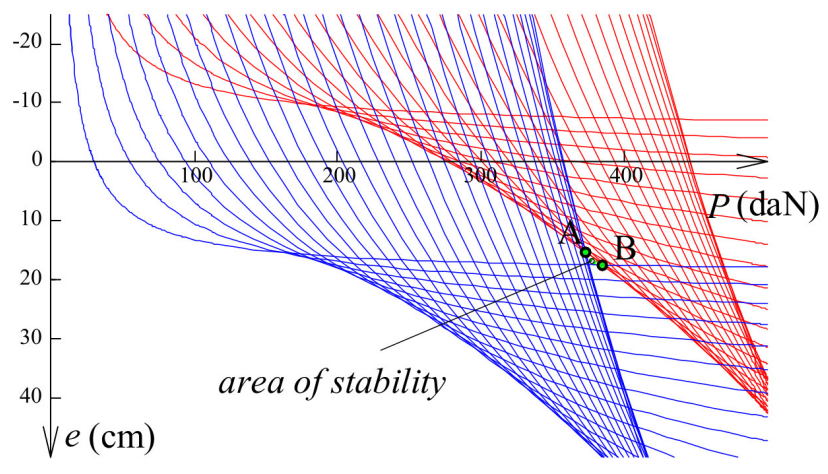

(A)

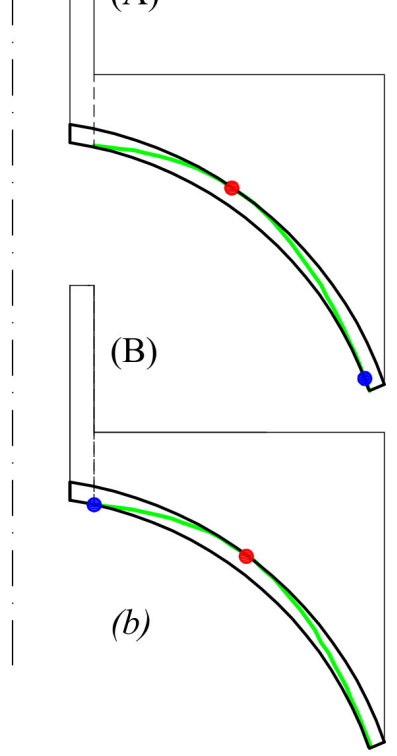

Fig. 5. The stability area related to the pendentive of maximum embrace angle, $\beta=70.79^{\circ}(a)$; the maximum and minimum thrust lines are contained within the lune, even if they almost coincide $(b)$.

The preliminary analysis performed up to now shows that equilibrium of the sail vault is guaranteed even if the vault is simplified into a series of adjacent arches without transverse connections. More advanced analyses will be conducted in order to better take into account the three-dimensional structural behaviour of sail vaults, as well as to find an adequate mechanical interpretation of any cracking and damage, asymmetries and geometric irregularities.

\section{CONCLUSIONS}

- The objective of the present research project is to describe the structural behaviour of a sail vault in Fortezza Vecchia by taking into account geometrical, mechanical and construction aspects.

- A detailed survey of the intrados surface has been carried out by means of a range-based (laser scanning) survey methodology. A post-processing procedure has been adopted in order to obtain the vault's intrados sections in CAD format and the analytically determined 'best' approximating smooth surfaces.

- A first investigation of the mechanical response of the sail vault in Fortezza Vecchia has been performed by means of a revised version of Durand-Claye's method. This involves appropriately slicing the sail vault by considering its central portion to be a dome of revolution, while the pendentives are modeled as a simple extension of the spherical shell constituting the dome.

- The analysis shows that equilibrium under vertical loads is guaranteed even under the assumption of nil compressive hoop forces.

- More advanced analyses will be performed in order to better take into account the threedimensional structural behaviour of the sail vault, as well as to find a suitable mechanical interpretation of the existing crack pattern. 


\section{ACKNOWLEDGMENTS}

Financial support from the University of Pisa under programme PRA 2017, project "Architetture toscane rinascimentali: casi studio fra indagine storica, rilievo e analisi strutturale" (Tuscan Renaissance architecture: case studies between historical investigation, survey and structural analysis) is gratefully acknowledged.

The collaboration of the Port System Authority of the Northern Tyrrhenian Sea is gratefully acknowledged.

The authors also wish to thank Prof. Andrea Piemonte for the laser scanner survey postprocessing elaborations.

\section{REFERENCES}

[1] Ulivieri, D. (2014) Fortezza Vecchia in Livorno, Nexus Netw J, 16:675-697.

[2] Durand-Claye A. (1880) Vérification de la stabilité des voûtes et des arcs. Applications aux voûtes sphériques, Annales des Ponts et Chaussées, 19, I sem., 416-440.

[3] Aita D., Barsotti R., Bennati S. (2019). Looking at the collapse modes of circular and pointed masonry arches through the lens of Durand-Claye's stability area method, Archive of Applied Mechanics. https://doi.org/10.1007/s00419-019-01526-Z

[4] Aita D., Barsotti R., Bennati S. (2017) A modern reinterpretation of Durand-Claye's method for the study of equilibrium conditions of masonry domes. AIMETA 2017 Proceedings of the XXIII Conference The Italian Association of Theoretical and Applied Mechanics, Salerno, Italy, 4-7 September 2017, L. Ascione, V. Berardi, L. Feo, F. Fraternali and A. M. Tralli (eds.), Gechi Edizioni, Mediglia (MI), 1459-1471.

[5] Aita D., Barsotti R., Bennati S. (2019) A parametric study of masonry domes equilibrium via a revisitation of the Durand-Claye method. In M. Papadrakakis, M. Fragiadakis (eds.), COMPDYN 2019, $7^{\text {th }}$ ECCOMAS Thematic Conference on Computational Methods in Structural Dynamics and Earthquake Engineering, Crete, Greece, 24-26 June 2019.

[6] Aita D., Barsotti R., Bennati S. (in press) Studying the dome of Pisa cathedral via a modern reinterpretation of Durand-Claye's method, JoMMS.

[7] Huerta, S. (2001) Mechanics of masonry vaults: The equilibrium approach. In Historical Constructions, P.B. Lourenço, P. Roca (eds.), Guimarães, 47-70.

[8] Heyman, J (1966) The Stone Skeleton. International Journal of Solids and Structures, Vol. 2, 249-79.

[9] Heyman, J. (1977) Equilibrium of shell structures. Oxford, Oxford University Press.

[10] Heyman, J. (1998) Structural analysis: a historical approach. Cambridge, Cambridge University Press.

[11] Heyman, J. (1999) The science of structural engineering. London: imperial College Press.

[12] Bouguer, P. (1734) Sur les Lignes Courbes propres a former les Voûtes en Dome. Mémoires de l'Académie Royale de Sciences de Paris, 149-166. 
[13] Frézier, A.F. (1737-39) La théorie et la pratique de la coupe de pierres [...]. Paris: C.A. Jombert. 3 vols.

[14] Block P., Ciblac T., Ochsendorf J.A. (2006) Real-time limit analysis of vaulted masonry buildings, Computers and Structures, doi:10.1016/j.compstruc.2006.08.002.

[15] D’Ayala D.F., Tomasoni E. (2008) The structural behaviour of masonry vaults: Limit state analysis with finite friction. In Structural Analysis of Historic Construction D’Ayala \& Fodde (eds.) Taylor \& Francis Group, London, ISBN 978-0-415-46872-5, pp. 47-61.

[16] D’Ayala D.F., Tomasoni E. (2011) Three-Dimensional Analysis of Masonry Vaults Using Limit State Analysis with Finite Friction. International Journal of Architectural Heritage, 5:140-171.

[17] Calderini C. (2004) Un modello costitutivo per la muratura: formulazione ed implementazione per l'analisi di strutture complesse. PhD Thesis, Dottorato di Ricerca in Ingegneria Strutturale e Geotecnica XVI Ciclo, Università degli Studi di Genova, DISEG Dipartimento di Ingegneria Strutturale e Geotecnica.

[18] Mousavian E. and Mehdizadeh Saradj F. (2018) Automated Detailing and Stability Analysis of Under-Construction Masonry Vaults, J. Archit. Eng., 2018, 24(3): 04018014, 1-15.

[19] Barsi F., Barsotti R., Bennati R. (2019), Equilibrium of masonry sail vaults: the case study of a subterranean vault by Antonio da Sangallo the Elder in the "Fortezza Vecchia" in Livorno. AIMETA 2019, XXIV Conference The Italian Association of Theoretical and Applied Mechanics, Rome, Italy, 15-19 September 2019.

[20] Barsotti R., Bennati S., Stagnari R. (2017) Analytical Determination of Statically Admissible Thrust Surfaces for the Limit Analysis of Masonry Vaults and Domes. AIMETA 2017 - Proceedings of the XXIII Conference The Italian Association of Theoretical and Applied Mechanics, Salerno, Italy, 4-7 September 2017, L. Ascione, V. Berardi, L. Feo, F. Fraternali and A. M. Tralli (eds.), Gechi Edizioni, Mediglia (MI), 14491458.

[21] Durand-Claye A. (1867) Note sur la vérification de la stabilité des voûtes en maçonnerie et sur l'emploi des courbes de pression. Ann. des Ponts et Chaussées, 13:63-93, 1867. 